\title{
RESUMO
}
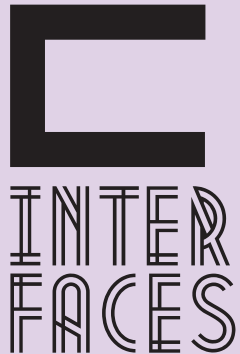

CIENTÍFICAS

\section{NEGROS, INTERNET E CIÊNCIA: A REPRESENTATIVIDADE E SUAS WEBCONEXÕES}

BLACK, INTERNET AND SCIENCE:

REPRESENTATIVITY AND ITS WEBCONNECTIONS

NEGRO, INTERNET Y CIENCIA: REPRESENTACIÓN Y SUS WEB CONEXIONES
Leandro Sant'Anna Santos ${ }^{1}$ Alexandre Meneses Chagas ${ }^{2}$
A população negra é uma das principais vítimas de discriminação. A falta de negros em campanhas publicitárias, em cargos de alto escalão, em produções científicas e em programas de pós-graduação contribuem para a diminuição de expectativas positivas para os negros. Com o acesso à internet o ambiente de discussão sobre esse assunto tem alcançado índices de audiência importantes e criado um ativismo capaz de movimentar a sociedade. Este artigo tem 0 objetivo de discutir a importância de debates sobre representatividade negra em ambientes científicos e cibernéticos, a fim de propagar as consequências disso para a população. A pesquisa é de caráter bibliográfico e exploratório e permitiu resultados como dados que tangem a desigualdade de negros na Ciência, nomes de importantes pesquisadores negros e informações relevantes para entendimento da conectividade e representatividade.

\section{PALAVRAS-CHAVE}

Discriminação. Negros. Produções científicas. Representatividade. 


\section{ABSTRACT}

The black population is one of the main victims of discrimination, the lack of blacks in advertising campaigns, high-level charges, scientific productions and graduate programs contribute to positive expectations for blacks. With access to the internet or a discussion environment on this subject, the important audience indexes are created as an asset capable of moving a society. Therefore, this article aims to discuss the importance of debates about black representativeness in scientific and cyber environments, in order to propagate as consequences of this for the population. The research is bibliographic and exploratory and allows results such as data that identify black inequalities in science, names of important researchers and relevant information to understand connectivity and representativeness.

\section{KEYWORDS}

Discrimination. BLACKS. Scientific productions. Representativeness.

\section{RESUMEN}

La población negra es una de las principales víctimas de la discriminación, la falta de negros en campañas publicitarias, en puestos de alto nivel, en producciones científicas y en programas de posgrado contribuye a la reducción de las expectativas positivas para los negros. Con acceso a internet, el ambiente de discusión sobre este tema ha alcanzado importantes cifras de audiencia y ha creado un activismo capaz de mover la sociedad. Por lo tanto, este artículo tiene como objetivo discutir la importancia de los debates sobre la representatividad negra en entornos científicos y cibernéticos, a fin de propagar las consecuencias de esto para la población. La investigación es de naturaleza bibliográfica y exploratoria y permite resultados como datos que tocan la desigualdad de los negros en la ciencia, nombres de investigadores negros importantes e información relevante para comprender la conectividad y la representatividad.

\section{PALABRAS CLAVE}

Discriminación. Negros. Producciones científicas. Representatividad. 


\section{INTRODUÇ̧̃̃o}

A firmação de uma cultura é de extrema importância para a construção e permanência de um povo, principalmente quando ele é marcado por lutas e resistências como os negros. Que historicamente é um povo que sofre constantes discriminações, onde sua cor é motivo de exclusão em escolas, ambientes de trabalho ou igrejas (MATTOS, 2007).

No Brasil, eles são mais da metade da população de 200 milhões de habitantes. Seus traços vindos da África em meados do século XVI para o Brasil colonial foi o início de uma história marcada por muitas feridas, suor e sangue. Uma dívida que o País carrega até hoje que, mesmo com o passar dos anos, o racismo enraizado na população brasileira, também a mundial, deturbam a vida de negros (TOKARNIA, 2019, ON-LINE).

O fato é que essa discriminação é vista nas mais diversas camadas que compõem uma sociedade, desde a família até a produção científica. Os ambientes políticos, escolares e econômicos são grandes espelhos do quanto essa população necessita juntar forças para resistir e lutar pelos seus ideais (MATTOS, 2007). Diante disso, a internet tem sido um espaço de constantes discussões e diálogos sobre questões raciais, mas não apenas, as pessoas têm a usado com maior frequência para expor suas opiniões sobre gênero, classes, meio ambiente, dentre outros temas.

Se por um lado, o meio virtual, conhecido como ciberespaço, extrapola fronteiras e dissemina uma "democracia" de ideias, por outro lado os usuários têm propagado um ódio gratuito e gerador de graves consequências, tanto para o afetado, quanto o agressor. Pois, mesmo a internet sendo acreditada como “território sem lei”, é possível encontrar rastros e determinar o culpado pelas agressões virtuais (FARIAS et al., 2017).

$O$ ato democrático que a web possibilitou é de grande valia para a construção de um pensamento crítico e analítico. Tendo em vista que o acesso ao conhecimento se torna mais fácil e ágil, ao disponibilizar materiais de discussões como artigos, livros, vídeos, podcasts e fóruns on-line. Para os negros isso é ainda mais valioso porque abre espaço para acessar conteúdos de firmação e representatividade. Por exemplo: quando um jovem negro vê na internet artistas, professores, cientistas ou demais profissionais que possuem a mesma cor que a dele, ocupando espaços majoritariamente brancos, é uma vitória, pois, alimenta as realidades de um povo e a esperança de também chegar aonde quiser.

Desse modo, o objetivo do trabalho é discutir a importância de debates sobre representatividade negra em ambientes científicos e cibernéticos, a fim de propagar as consequências disso para a população, a partir de uma pesquisa de caráter bibliografo e exploratório. É válido identificar o alcance e implicações que os comentários e produções preconceituosas nas redes sociais geram. De modo que, é preciso entender as perspectivas que os negros tomam ao se deparar com conteúdo on-line que dizem respeito a sua identidade e luta.

Por isso, diante do pequeno número de pesquisadores e pós-graduandos negros no Brasil, faz-se necessário desenvolver pesquisas que possam discutir a importância de representatividade negra, principalmente diante da ascensão de registros na web sobre racismo e poder negro. $O$ fato é que, as pessoas precisam debater mais o que a internet possibilita para a cultura e identidade de um povo. 
Portanto, a pesquisa busca alertar sobre a realidade que os negros enfrentam em rede e fora dela. Ao mesmo tempo em que mostre alternativas de incentivar atitudes de Ciência diversificada e modificar a concepções enraizadas ao preconceito, que restringe o povo preto a um ser incapaz ou excluso das evoluções tecnológicas. Para isso, na primeira seção são apresentados dados e situações que diferem a realidade dos negros e brancos. Na segunda seção, inicia o papel da propagação da Ciência e internet para negros, para que, na terceira seção, assuntos como Divulgação Científica seja explorada. Por fim, são feitas as devidas considerações.

\section{MAISNEGROSNACIENCIA.COM}

Pensar sobre Ciência pode ser direcionada para um movimento de pré-conceito sobre a figura do pesquisador, como homem branco, de jaleco e óculos. Esse tipo de estereótipo, também propagado na indústria cinematográfica, fortalece a falta de conhecimento e representatividade de negros e negras que participam do processo e são, também, protagonistas de pesquisas científicas. Quando produções desse público ou descobertas que servem de retaliação com o povo "afro" são publicadas, novos interesses podem ser despertados.

A responsabilidade da Ciência nesse quesito é significativa porque suas percepções e iniciativas abrem espaço para o entendimento do que a educação pode proporcionar para um público marginalizado (PORTO; OLIVEIRA; ROSA, 2018). Descobrir que figuras importantes para a história eram negras é um ato de representatividade e retaliação sobre o embranquecimento daquele personagem, como a análise de historiadores que acreditam que a figura do salvador dos homens, o Jesus Cristo, não seria branco, como é caracterizado nas pinturas, responsáveis pela criação de um Jesus europeu, com cabelos longos, de pele e olhos claros.

O estudo aponta que o nazareno teria o aspecto da população da sua terra no Oriente Médio. Importante lembrar que, os homens daquela região possuíam pele escura, outros estudos também apontam essa característica, ou seja, o filho de Deus é na verdade negro (VEIGA, 2019, ON-LINE).

Essa descoberta não é a única sobre a verdadeira cor de ícones da nossa história. Um dos maiores literários do Brasil, o Machado de Assis, também foi representado como negro. Ações assim abrem espaços de discussão e garante à sociedade o conhecimento da grandeza de pessoas negras que contribuíram para a construção da cultura (ILHÉU, 2019, ON-LINE). Nesse quesito a internet possibilita que mais pessoas possam saber a respeito e tomem proveito disso para propagar a cultura negra. Muitas empresas percebem a importância desse movimento e dão espaço a pessoas pretas em campanhas publicitárias, novelas, filmes e programas de TV, o que eleva a autoestima delas e daquelas que nunca se sentiram representadas.

Porém, em momentos assim se percebe como a internet comporta-se de uma maneira negativa. A exemplo o comercial de Dias dos Pais, da marca 0 Boticário, que colocou uma família negra como protagonista, em que não se percebia nada de diferente das outras famílias "tradicionais" retratadas em outras propagandas. Apesar da linguagem leve e de humor, o vídeo recebeu mais de 16 mil dis- 
likes no YouTube e inúmeros comentários racistas. Apesar disso o número de curtidas foi 3x maior. (SANDIN, 2019, ON-LINE).

Diversos são os casos de discriminação, tendo como espaço as redes sociais e sites da internet. Seja o simples fato de a atriz Taís Araújo abordar o racismo em sua fala na palestra do TED em que menciona que a cor de seus filhos é motivo para outras pessoas desviarem da rota (G1, 2019, ON-LINE). Ou ainda, colocar uma atriz negra para representar a personagem de quadrinhos Estelar que veio do espaço e possui uma cor alaranjada na série de Titãs da Netflix (REVISTA GALILEU, 2019, ON-LINE). Ambos os casos foram motivo de remoque e preconceito racial que gerou muita repercussão na web e até memes caracterizando o racismo.

Por isso, discutir representatividade é tão importante. Quanto mais negros ocuparem as mais variadas áreas, mais chances de diminuir o pensamento opressor. No entanto o caminho ainda é longo. Nas áreas de Ciência e Tecnologia, a população negra ainda não possui níveis significativos de participação, a exemplo de que em 2016 , os brancos ocupavam $90 \%$ na área de engenharia de equipamentos na computação, segundo o Ministério do Trabalho (SOARES, ON-LINE 2019). Isso, também, é reflexo das desigualdades sociais, que excluem e determinam quem pode acessar as universidades. Com o sistema de cotas os negros tiveram a oportunidade de ocupar esses espaços e maiores chances de alcançar uma profissão digna.

O número de negros nas universidades e programas de pós-graduação é preocupante. Apenas cerca de $34 \%$ deles acessam as universidades, sendo que $12,8 \%$ desses alunos têm entre 18 e 24 anos (IBGE, 2015). Quando isso se estende ao doutorado, a situação fica ainda pior. Segundo o Censo da Educação Superior de 2016, mulheres pretas nesse sistema são 0,4\% do corpo docente (FERREIRA, 2019, ON-LINE).

Ter pesquisadores negros é um grande passo para a diversidade nas produções científicas e desenvolvimento de dispositivos inovadores que atendam a demanda desse público. A fim de impedir que casos como do vídeo que foi compartilhado no Twitter, tendo 183 mil curtidas e compartilhado 136 mil vezes, não ocorra. Este vídeo apresentava o fato de uma saboneteira automática não funcionar em pele negra, apenas branca. A questão é que seus desenvolvedores não buscaram a diversidade de peles e isso ocasionou uma repercussão muito negativa na internet (O GLOBO, 2019, ON-LINE).

A diversidade nas tecnologias é primordial para um sentimento de pertencimento de um público. Como o estudo de maquiagens com várias tonalidades da pele, que tornou possível a produção desses materiais na indústria e livrado o fardo das mulheres e homens negros da procura de produtos que aderissem à sua cor. Apoio e discussão de temas assim em centros de pesquisa e mídias sociais podem ampliar a diversidade de saberes e experiências. As comunidades nas redes são formas de compartilhar tais situações e buscar alternativas de melhorias para a população.

0 ativismo digital, uma forma de expressão social por meio da internet, tem ganhado espaço e potencializado movimentos de lutas contra o preconceito, como a do povo negro. Diante da dificuldade de estar presente fisicamente nas concentrações desses movimentos, as redes sociais se tornaram ambientes propícios para discutir e apresentar ideologias e agendas sobre o assunto. É válido perceber que a internet por si só não é capaz de acabar com o racismo, mas o seu alcance pode ampliar a discussão e chegar em campos inimagináveis. 0 movimento pela liberdade de Rafael Braga que 
atingiu dimensões internacionais é um exemplo. Trata-se de um caso sobre um jovem negro que foi abordado por policiais e foi preso por suspostamente portar material explosivo, que seriam coquetéis-molotov (BUENO, 2020, ON-LINE).

O fato é que a conectividade tem permitido maiores campos de discussão e divulgação de assuntos voltados à luta e à representatividade negra. A revista Galileu, em seu site, publicou uma lista de vinte e três cientistas negros que todos precisam conhecer, nomes como: Alfred Oscar Coffin (1861 - 1933), primeiro afro-americano a ser doutor em biologia; Ernest Everett Just (1883 - 1941), responsável pelo estudo que reconhece a importância da superfície celular no desenvolvimento dos organismos; Katherine Johnson (1918), tida como uma "calculadora humana", era uma cientista espacial norte-americana, que contribuiu para a aeronáutica e exploração espacial dos Estados Unidos, em especial em aplicações da computação na NASA. Também recebeu a Medalha Presidencial da Liberdade em 2015, a maior condecoração civil dos Estados Unidos. Outro nome importante é o Neil de Grasse Tyson (1958), um dos astrofísicos mais famosos, colecionou prêmios de Divulgação Científica e apresentou a indispensável série Cosmos: Uma Odisséia do Espaço-tempo. Na lista também tem a presença do brasileiro, Milton Santos (1926 - 2001), foi o primeiro brasileiro a ganhar o Prêmio Vautrin Lud, espécie de Nobel da geografia (LOPES, 2020, ON-LINE).

\section{3 \#NEGROSNOTOPO}

Diante de debates e produções que permitem a abertura de espaços para negros, a escola é um dos principais ambientes que deve ensinar o aluno a entender e respeitar a diversidade. No ensino de Ciências, a abordagem parte de presunções de caráter europeu a exemplo os alquimistas precursores da Química, sendo relacionados somente a Europa, o que desconsidera o conhecimento químico no Egito Antigo para embalsamar os corpos dos faraós egípcios.

Por isso a releitura sobre a Ciência é fundamental, apesar de ser um difícil caminho, diante de poucos dados sobre os conhecimentos forjados na África, reflexo da supervalorização europeia. Mas, graças a conectividade, a busca por referências e conhecimentos científicos por parte ou para negros, podem ser aplicados em aula, cabe ao professor tomar a iniciativa em conjunto com os alunos e discutir (JUNIOR, 2008).

A abertura de um diálogo entre a Ciência e Sociedade permite que o desconhecimento sobre os avanços científicos seja reduzido e desperte o interesse em aprender mais. A Divulgação Científica é um exemplo, por meio de eventos, redes sociais, revistas, jornais e tantas outras opções. Trata-se de uma atividade pertencente a difusão científica, reponsabilidade que o pesquisador deve exercer. $\mathrm{Na}$ difusão temos a Divulgação e a Disseminação, a primeira o que tende a ser relação pesquisador-leigo e a segunda é pesquisador-pesquisador (PORTO; OLIVEIRA; ROSA, 2018). Todas essas atividades são extremamente importantes para o crescimento da visibilidade negra e produções de cientistas negros.

Ao que interessa as produções de cientistas negros, a matrícula e permanência deles na pós-graduação (mestrado e doutorado), abre espaço para que estudos por eles desenvolvidos sejam pu- 
blicados, discutidos e disseminados entre pares. Esse efeito traz bons resultados para a sociedade, pois, ao ter pesquisadores negros, as chances de debater temas sobre sua existência e resistência são maiores, além de criarem uma visão de representatividade, o que faz com que jovens despertem interesse e sigam carreira. No que tange a divulgação das pesquisas científicas, a sua linguagem deve possuir uma identidade e própria para o entendimento do público que não é cientista ou pesquisador. Utilizar mídias como Instagram, Facebook e demais presentes na web, permite um contato mais prático com a sociedade, isso graças as constantes mudanças sentidas por ela diante das tecnologias de informação e digitais, o que cria uma Cibercultura.

A nova potência da emissão, da conexão e da reconfiguração, os três princípios maiores da Cibercultura estão fazendo com que possamos pensar de maneira mais colaborativa, plural e aberta. Sempre que podemos emitir livremente e nos conectar a outros, cria-se uma potência política, social e cultural: a potência da reconfiguração e da transformação. A cultura contemporânea, do digital e das redes telemáticas, está criando formas múltiplas e multimodais e planetárias de recombinações. (LEMOS; LEVY, 2010, p. 27).

Ou seja, os avanços da conectividade têm transformado os modelos de discurso, o alcance e outros indicadores importantes para uma discussão política e étnica-racial. Os exemplos abordados são situações claras dessas mudanças. 0 poder que a internet tem hoje é capaz de causar grande mudanças e movimentos de alcance internacional. 0 uso de celulares e outros equipamentos móveis de acesso à internet melhoram a praticidade de contato com a informação, assim, notícias podem ser acessadas em tempo real e discutida entre interessados.

O tema racismo, por exemplo, é algo muito pesquisado na internet, sendo o mês de novembro, dedicado a consciência negra, o período em que as buscam dobram, cerca de $120 \%$ de maior interesse em comparação com os outros meses do ano, segundo o Google (METRO JORNAL, 2020, ON-LINE). Esse tipo de informação só fortalece a falta de preocupação das pessoas e empresas em desenvolver métodos antirracistas e inclusivos, pois, ao que se parece a representatividade negra só deve acontecer no mês de novembro, ou ainda, no dia 20, data determinada para o assunto.

A cultura de povo precisa se manter viva, de modo que mais pessoas entendam a importância da diversidade para uma sociedade como um todo. 0 exercício da educação é uma ação primordial para a mudança das estatísticas negativas sobre a população preta. A taxa de analfabetismo é mais que o dobro entre pretos e pardos $(9,9 \%)$ do que entre brancos (4,2\%), de acordo com a Pesquisa Nacional por Amostra de Domicílios Contínua (PNAD) Contínua (IBGE, 2016); o desemprego referente ao $3^{\circ}$ trimestre de 2018 registrou um índice mais alto entre pardos (13,8\%) e pretos (14,6\%); e 76,2\% das vítimas de atuação da polícia são negras (CALEIRO, 2020, ON-LINE).

A escola é um ambiente que pode mudar isso, a partir do momento em que o professor e aluno entendem a importância do respeito e capacidade de negros chegarem em posições de alto escalão. Compreender a realidade do aluno e suas circunstâncias também fazem toda diferença no ensino, de maneira que a realidade que o afeta pode ser debatida. 
Deste modo, o ensinar sempre preconiza o aprender, e vice-versa, sendo ambos, educador e educando, sujeitos do processo. Defendendo que a educação seja concebida com base na realidade do educando, isto é, por meio de algo que faça sentido ao educando, e permita, deste modo, uma forma de intervenção no mundo e transformação da realidade, Freire pondera tal realidade como experiência histórica, existencial, no mundo e com o mundo, pois, estar no mundo implica necessariamente estar com o mundo e com os outros, de tal modo que os homens em comunicação e intercomunicação "vão se percebendo, criticamente, como estão sendo no mundo com que e em que se acham" (FREIRE, 2005, p. 82).

Não há como eliminar a historicidade do mundo, a realidade é o contexto histórico, social e cultural na qual os seres humanos interferem por meio de uma relação inexoravelmente dialética. (JUNIOR, 2008, p. 409).

A linha de pensamento do estudioso Paulo Freire leva a identificar pontos que contribuem para a discussão sobre racismo, pois, ao entender que um aluno negro, da periferia está sujeito a situações de alto risco e discriminação, aprender que sua realidade pode ser transformada por meio de um ensino crítico e realista e que permite a valorização da cultura negra, possivelmente eleva as chances de um futuro melhor.

Porém, algumas questões ainda não são maturadas no Brasil, como o entendimento sobre racismo. Admitir que ele existe é um passo muito importante para que mudanças aconteçam. Segundo o IBOPE, dois em cada dez brasileiros admitem ser preconceituosos, porém, 46\% dos entrevistados já cometeram ou ouviram declarações racistas (DIÓGENES; CASTANHO, 2017). Esses dados comprovam que atitudes racistas existem, mas as pessoas que cometem não se consideram como tal.

Assim, a população negra do país tem sido subjugada, violentada e criminalizada desde a escravidão para saciar os interesses sociais e econômicos das classes ricas - fenômeno acolhido por leis cujos efeitos camuflam, revalidam e perpetuam a opressão. A propagação do discurso preconceituoso e discriminatório alicerça a narrativa para desqualificar a cidadania afrodescendente. 0 discurso da acomodação, que afirmava serem os(as) negros(as) acomodados(as) com sua situação e condição, os considerava vítimas com defeitos. Por isso, eram tratados como infantilizados e deles retirada sua humanidade. Desta forma, fez com que as desvantagens que se acumularam fossem associadas à cor da pele, de um povo dado à escravidão e mal ajustado. (MADEIRA; GOMES, 2018, p. 464-465).

Desse modo, as abordagens como essas camuflam uma realidade marcada pelo racismo, com ações políticas e sociais como instrumento ideológico de controle social, inibindo que negros tenham uma projeção de vida semelhante aos brancos. Com isso, abrir espaços de debates sobre igualdade, inclusão e racismo é fundamental para a mudança do conhecimento da sociedade. As representatividades e apoio científico nesse momento precisam ser mais fortes e competentes ao ponto de negros ocuparem espaço antes pertencentes aos brancos.

0 racismo abre um abismo social na sociedade brasileira, um problema que assola o âmbito interpessoal, comportamental, político, econômico, educacional e social. Por isso a importância 
de observar as singularidades históricas e avanços científicos, de modo que seja identificado formas de diminuir as ações preconceituosas. O movimento negro tem conquistado cada vez mais seu espaço, mas diante dos dados desigualdade ainda tem muito a ser feito para mudar essa situação (MADEIRA; GOMES, 2018).

\section{CIÊNCIA PARA O POVO! POVO NEGRO}

Ao levar a Ciência para a sociedade as chances de acesso ao conhecimento aumentam e possibilitam espaços de discussão. Conforme já mencionado, o pesquisador tem um papel fundamental ao levar descobertas para pessoas leigas, principalmente quando o assunto diz respeito ao povo negro, que tem um histórico de negação, de discriminação no acesso e produções científicas. Por isso, a Divulgação Científica tem sido discutida em muitas vertentes acadêmicas, em grupos de pesquisa e dentro da própria comunidade científica, com o objetivo de tornar as novidades científicas mais populares, a partir disso, as redes sociais são exemplos de comunicação direta com o público da internet, nestes espaços os pesquisadores se eximem da responsabilidade de avaliação científica, porém ainda precisam tratar com muito cuidado as informações repassadas (PORTO; OLIVEIRA; ROSA, 2018).

Há inúmeros exemplos bem sucedidos de divulgação científica pelas mídias sociais e estudiosos destas novas alternativas têm, com frequência, nos últimos dez anos, destacado alguns destes casos. Tayta Singer (2015) descreveu e analisou com detalhes a experiência da bióloga britânica Elise Andrew que criou, em 2012, a página I Fucking Love Science para divulgar informações, fotos curiosas e inclusive quadrinhos e memes de conteúdo científico, conseguindo, em três anos, atrair cerca de 20 milhões de fãs. Logo depois criou também um perfil de Twitter e um canal do You Tube, reunindo nos dois casos, centenas de milhares de seguidores. (PORTO; OLIVEIRA; ROSA, 2018, p. 64).

Esses exemplos são importantes, pois permitem que pesquisadores busquem novas alternativas para levar produções científicas à população. Dentre todos os seus papéis com a Ciência, o pesquisador também deve à população uma resposta quanto ao que está sendo descoberto e estudado. 0 público geral precisa possuir um contato com essas produções científicas, porque assim o conhecimento é gerado e propagado. Com isso é importante ampliar a divulgação e como ela hoje está sendo feita, principalmente dentro da Cibercultura.

Porém, esses divulgadores em questão são brancos, a dificuldade de encontrar negros que realizem esse papel é enorme. Em 2019, uma mesa-redonda com o tema "O negro na Ciência brasileira”, foi discutido na Universidade Federal do Mato Grosso do Sul (UFMS). O pesquisador Henrique Antunes Cunha Júnior, da Universidade Federal do Ceará (UFC), apresentou uma lista de negros e negras que obtiveram importantes atuações na Ciência brasileira e debateu a importância de se investir na formação de profissionais negros. Ele mencionou que apenas 5 mil pesquisadores para um total de 192 mil pesquisadores no Brasil, são negros (UFMS, 2020, ONLINE). 
Nesse cenário as universidades são ambientes essenciais na produção científica, sendo também responsável pelas descobertas e estudos que interferem no desenvolvimento de um país. Para perceber a tamanha importância dessas instituições, mais da metade da pesquisa científica no País é desenvolvida por universidades públicas. Segundo o relatório da empresa Clarivate Analytics a produção científica no Brasil cresceu 30\% entre 2013 e 2018 (JORNAL GGN, 2019, ON-LINE).

É essencial, no processo de divulgação científica, a necessária reflexão sobre as relações de poder que envolvem a produção científica. Não se trata, obviamente, de demonizar os diferentes atores sociais que envolvem a política científica do país, seja a comunidade científica, o governo, o setor produtivo, mas garantir a polifonia das vozes, considerando o papel e o poder da mídia na formação do imaginário social, calcado em uma aldeia global, em que tudo se articula em teias multimídias, com informações fragmentadas, destituídas de contexto, sem uma perspectiva histórica, que permita interligar o presente ao passado, estabelecendo correlações para uma perspectiva futura. (CALDAS, 2011, p. 26).

Assim, o pesquisador tem o dever de criar, sair das universidades, a fim de expandir os espaços de conhecimento, em que de fato se preocupe com a divulgação das suas pesquisas. E, em meio a Cibercultura, o conhecimento científico pode ser expandido e introduzido na vida das pessoas com um simples clique, só é preciso que a comunidade científica entenda a importância disso e conduza suas ações ao bem comum.

Um dado positivo diante da situação da Ciência no Brasil, pesquisas brasileiras sobre racismo e desigualdade racial crescem 28 vezes em 20 anos. 0 que antes em 1999 era de cinco artigos, em 2018 cresceu para 147. Assuntos como Marielle Franco, papel da mulher em movimentos feministas e na medicina, foram alguns assuntos abordados. O levantamento foi feito pela Folha a partir da Web of Science, que possui informações a nível global de produções científicas, apresentando assim o Brasil como o quinto país que mais discute temáticas do gênero (ALVES; GAMBA, 2020, ON-LINE)

Assim sendo, a luta contra o preconceito por meio de produções científicas tem tido índices interessantes, que servem de materiais para outros pesquisadores e professores que desejam abrir espaço para uma discussão profunda e embasa em dados e conceitos que permitem que tanto o emissor, quanto o receptor da mensagem tenham contato com a realidade de muitos negros e avanços por eles desenvolvidos na área da Ciência e Tecnologia.

\section{CONCLUSÃO}

Portanto, a população negra tem muito para conquistar e precisa de apoio das mais variadas estâncias que compõe uma nação. $O$ fato de ter alguns negros na televisão não quer dizer que o racismo acabou, muito menos que estamos presentes em todos os espaços. Em comparação com os brancos, a representatividade negra ainda precisa de muito. A internet é um meio fundamental para que a discussão sobre isso seja fortalecida e expandida. 
Quando a Ciência se mostra atenciosa quanto as demandas dos negros, a possibilidade de mudança nas áreas acadêmicas pode ser positiva, apesar do baixo índice de alunos negros pesquisadores, sua luta por espaço é significativa e permeia na mente de outros que desejam inovar e contribuir para a produção científica. Mas é preciso que informações como essas sejam transmitidas para o povo leigo e discutida em canais e espaços diversos, como redes sociais e escolas.

Desse modo, conclui-se que os negros apesar de maioria enquanto quantidade no Brasil, sua representatividade na Ciência ainda é pequena e o povo brasileiro permeia o preconceito nas redes sociais e fora delas. Um ponto positivo é que discussões sobre racismo e representatividade têm ganhado espaço, seja pelas produções científicas ou pelos discursos e eventos presenciais e cibernéticos. Quando os estudos apontam o impacto social do racismo eles tendem a ganhar relevância. 0 dado apresentado sobre a quantidade de produções de temática racismo no Brasil, só fortalece a sua existência e que precisa ser combatido, em conjunto com os órgãos públicos, sociedade comum e científica.

\section{REFERÊNCIAS}

15 UNIVERSIDADES públicas produzem 60\% da ciência brasileira. Jornal GGN, 2019. Disponível em: https://jornalggn.com.br/noticia/15-universidades-publicas-produzem-60-da-cienciabrasileira/. Acesso em: 20 dez. 2010.

ALVES, Gabriel; GAMBA, Estêvão. Pesquisas brasileiras sobre racismo e desigualdade racial crescem 28 vezes em 20 anos. Folha de São Paulo, 2019. Disponível em: https://www1.folha.uol.com.br/ ciencia/2019/11/pesquisas-brasileiras-sobre-racismo-e-desigualdade-racial-crescem-28-vezes-em20-anos.shtml. Acesso em: 19 jan. 2020.

ATRIZ DA SÉRIE ‘TITÃS’ sofre ofensas racistas de fãs de quadrinhos. Revista Galileu, 2018. Disponível em: https://revistagalileu.globo.com/Cultura/noticia/2018/07/atriz-da-serie-titas-sofreofensas-racistas-de-fas-de-quadrinhos.html. Acesso em: 7 out. 2019.

ATRIZ TAIIS ARAÚJO é alvo de comentários racistas em rede social. G1, Rio de Janeiro, 2016. Disponível em: http://g1.globo.com/rio-de-janeiro/noticia/2015/11/atriz-tais-araujo-e-alvo-decomentarios-racistas-em-rede-social.html. Acesso em: 7 out. 2019.

BUENO, Winnie. 0 ativismo negro no mundo virtual. Medium, 2016. Disponível em: https://medium. com/@winniebueno/o-ativismo-negro-no-mundo-virtual-f7e0d1d024b2. Acesso em: 20 jan. 2020.

BUSCA POR ‘RACISMO’ mais que dobra em novembro, segundo

Google. Metro Jornal, 2019. Disponível em: https://www.metrojornal.com.br/estilovida/2019/11/20/dia-da-consciencia-negra-busca-racismo-google.html. Acesso em: 19 jan. 2020. 
CALDAS, Graça. Mídia e políticas públicas para a comunicação da ciência. In: PORTO, Cristiane de Magalhães; BROTAS, Antonio Marcos Pereira; BORTOLIERO, Simone Terezinha (org.). Diálogos entre ciência e divulgação científica: leituras contemporâneas. Salvador: EDUFBA, 2011.

CALEIRO, João Pedro. Os dados que mostram a desigualdade entre brancos e negros no Brasil. Exame, 2018. Disponível em: https://exame.abril.com.br/brasil/os-dados-que-mostram-adesigualdade-entre-brancos-e-negros-no-brasil/. Acesso em: 18 jan. 2020.

DIÓGENES, Juliana; CASTANHO, William. Só 2 em cada 10 brasileiros admitem ser preconceituosos, diz pesquisa do IBOPE. Estadão, 2017. Disponível em: https://brasil.estadao.com.br/ noticias/geral,so-2-em-cada-10-brasileiros-admitem-ser-preconceituosos-diz-pesquisa-doibope,70002034390>. Acesso em: 18 jan. 2020.

FARIAS, Jorge Wambaster Freitas et al. Racismo e julgamento social na internet: crianças e jovens negros como alvos. Bvsalud, 2017. Disponível em: http://docs.bvsalud.org/ biblioref/2018/01/877418/20107-49933-3-pb.pdf. Acesso em: 8 out. 2019.

FERRERA, Lola. Menos de 3\% entre docentes da pós-graduação, doutoras negras desafiam racismo na academia. Portal Geledés, 2019. Disponível em: https://www.geledes.org.br/menos-de-3-entredocentes-da-pos-graduacao-doutoras-negras-desafiam-racismo-na-academia/. Acesso em: 9 out. 2019.

IBGE - Instituto Brasileiro de Geografia e Estatística. Pesquisa Nacional por Amostra de Domicílios Contínua (PNAD). 2016. Disponível em: https://www.ibge.gov.br/estatisticas/multidominio/condicoesde-vida-desigualdade-e-pobreza/17270-pnad-continua.html?=\&t=o-que-e. Acesso em: 20 jan. 2020.

ILHÉU, Taís. Faculdade colore foto de Machado de Assis para lembrar que ele era negro. Guia do Estudante, 2019. Disponível em: https://guiadoestudante.abril.com.br/estudo/faculdade-colorefoto-de-machado-de-assis-para-lembrar-que-ele-era-negro/. Acesso em: 8 out. 2019.

JUNIOR, Wilmo Ernesto Francisco. Educação anti-racista: reflexões e contribuições possíveis do ensino de ciências e de alguns pensadores. Scielo, 2008. Disponível em: http://www.scielo.br/pdf/ ciedu/v14n3/a03v14n3.pdf. Acesso em: 19 jan. 2020.

LEMOS, André; LÉVY, Pierre. 0 futuro da Internet: em direção a uma ciberdemocracia planetária. São Paulo: Paulus, 2010.

LOPES, Larissa. 23 cientistas negros que você precisa conhecer. Revista Galileu, 2018. Disponível em: https://revistagalileu.globo.com/Ciencia/noticia/2018/12/23-cientistas-negros-que-voceprecisa-conhecer.html. Acesso em: 12 jan. 2020. 
MADEIRA, Zelma; GOMES, Daiane Daine de Oliveira. Persistentes desigualdades raciais e resistências negras no Brasil contemporâneo. Scielo, 2018. Disponível em: http://www.scielo.br/ pdf/sssoc/n133/0101-6628-sssoc-133-0463.pdf. Acesso em: 18 jan. 2020.

MATTOS, Regiane A. História e cultura afro-brasileira. São Paulo: Contexto, 2007.

PORTO, Cristiane; OLIVEIRA, Kaio Eduardo; ROSA, Flavia. Produção e difusão de ciência na

Cibercultura: narrativas em múltiplos olhares. Ithéus: Editus, 2018.

SANDIN, Caio. Comercial de Dia dos Pais com família negra causa polêmica. R7, 2019. Disponível em: https://noticias.r7.com/prisma/r7-planalto/comercial-de-dia-dos-pais-com-familia-negracausa-polemica-26042019. Acesso em: 8 out. 2019.

SOARES, Iraema. Como a ausência de negros trabalhando em tecnologia impacta os produtos criados para facilitar nosso dia a dia. Gauchazh, 2019. Disponível em: https://gauchazh.clicrbs. com.br/tecnologia/noticia/2019/04/como-a-ausencia-de-negros-trabalhando-em-tecnologiaimpacta-os-produtos-criados-para-facilitar-nosso-dia-a-dia-cju32g40e00x001 nvv1495xmq.html. Acesso em: 7 out. 2019.

TOKARNIA, Mariana. Racismo prejudica produção científica de pesquisadores negros no Brasil. Agência Brasil, 2015. Disponível em: http://agenciabrasil.ebc.com.br/educacao/noticia/2015-05/ racismo-prejudica-producao-cientifica-de-pesquisadores-negros-no-brasil. Acesso em: 6 out. 2019.

UFJF - Universidade Federal de Juiz de Fora. Consciência Negra: apenas 34\% dos alunos de ensino superior são negros no Brasil. UFJF, 2017. Disponível em: https://www2.ufjf.br/ noticias/2017/11/20/consciencia-negra-apenas-34-dos-alunos-de-ensino-superior-sao-negros-nobrasil/. Acesso em: 9 out. 2019.

UFMS - Universidade Federal de Mato Grosso do Sul. SBPC Afro e Indígena: representatividade de pessoas negras na ciência brasileira é debatida. UFMS, 2019. Disponível em: https://www.ufms. br/sbpc-afro-e-indigena-representatividade-de-pessoas-negras-na-ciencia-brasileira-e-debatida/. Acesso em: 20 jan. 2020.

VEIGA, Edison. 0 que os historiadores dizem sobre a real aparência de Jesus. BBC, 2018. Disponível em: https://www.bbc.com/portuguese/geral-43560077. Acesso em: 8 out. 2019.

VÍDEO COM SABONETEIRA levanta debate sobre 'tecnologias racistas'. O Globo, 2017. Disponível me: https://oglobo.globo.com/economia/video-com-saboneteira-levanta-debate-sobre-tecnologiasracistas-21720614. Acesso em: 9 out. 2019. 
1 Mestrando em Educação - Linha Educação e Comunicação, bolsista (PROCAPS/TAXA) pela Universidade Tiradentes - UNIT. Graduado em Comunicação Social: Publicidade e Propaganda - UNIT. Membro do Grupo de Pesquisa em Educação, Tecnologias da Informação e Cibercultura (GETIC/UNIT/CNPq). E-mail: leandro_sants97@hotmail.com

2 Doutor em Educação (UNIT), Professor do Programa de Pós-Graduação em Educação da Universidade Tiradentes (Unit/PPED). É professor do Curso de Comunicação Social da Universidade Tiradentes - Unit, Supervisor de Estágio e TCC do Curso de Comunicação Social da Universidade Tiradentes - Unit. E membro do grupo de Pesquisa e Estudos em Educação, Comunicação e Sociedade (GECES/UNIT/ CNPq), e do Grupo de Pesquisa Educação, Tecnologia da Informação e Cibercultura (GETIC/UNIT/CNPq). Dedica-se ao estudo de Práticas Pedagógicas na Cibercultura, utilização de aplicativos no processo de aprendizagem significativa. E-mail: profamchagas@gmail.com

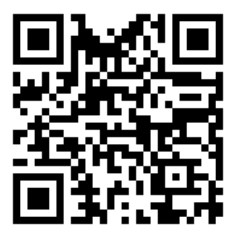

A autenticidade desse artigo pode ser conferida no site https://periodicos. set.edu.br

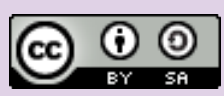

Este artigo é licenciado na modalidade acesso abertosob a Atribuição-Compartilhalgual CC BY-SA

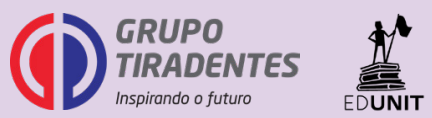

